\title{
1821: La celebración de la Independencia del Perú en Santiago de Chile
}

\section{1: The celebration of the Independence of Peru in Santiago de Chile}

Susy Sánchez Rodríguez ${ }^{1}$

\section{Resumen}

Este artículo se centra en la celebración de la independencia del Perú en la ciudad de Santiago de Chile durante el mes de agosto de 1821, empleando, principalmente la información del diario oficial denominado Gazeta Ministerial de Chile. Se analiza el intenso ciclo festivo que produjo la denominada $l i-$ beración de Lima, ocurrida el 10 de julio del mencionado ańo, cuando las fuerzas patriotas, bajo el mando del general San Martín, ingresaron en la ciudad. La primera parte presenta el profundo vínculo simbólico entre la liberación de Lima y el desastre sufrido por los patriotas en la batalla de Rancagua en 1814. La segunda parte presenta cómo la celebración de la independencia del Perú sublimó la legitimidad política y simbólica del director supremo, Bernardo O’Higgins, quien se convirtió en un heroico líder continental y la encarnación de una nación triunfante.

1 PhD en Historia por la Universidad de Notre Dame, en Indiana, EE.UU. y magíster en historia por la Pontificia Universidad Católica del Perú (PUCP). Especialista en historia social y cultural en el Perú, México y Centroamérica, para los siglos XVIII, XIX y XX. Tiene en su haber investigaciones sobre el terremoto de 1746 desarrollando el papel de las procesiones, las diversiones y el miedo. Correo: ssanche7@gmail.com. ORCID: 0000-0002-5663-0947 
Palabras clave: guerra de Independencia, Lima, Santiago de Chile, San Martín, O’Higgins, Rancagua

\section{Abstract}

This article focuses on the celebration of the Peruvian Independence in the city of Santiago de Chile in August 1821. It mainly examines the official newspaper, Gazeta Ministerial de Chile. This work establishes the intense festivities that produced the so-called liberation of Lima, which occurred on July 10,1821 . On this date, the patriotic forces under the command of General San Martín entered the city. The first part shows the highly symbolic link between the identified liberation of Lima from the royalist forces with the "disaster of Rancagua." The "liberation of Lima" led to a resignification of the commemoration of the battle of Rancagua. The second part demonstrates how the set celebration of the Peruvian Independence sublimized the political and symbolic legitimacy of the Supreme Director, Bernardo O'Higgins, who became a heroic continental military figure, turning him into the embodiment of a triumphant nation.

Key words: Independence War, San Martín, Bernardo O' Higgins, Lima, Rancagua

\section{Introducción}

En agosto de 1821, el ritmo cotidiano de los habitantes de la ciudad de Santiago de Chile se alteró con el anuncio y la celebración de la noticia de la liberación de la capital virreinal peruana. Las tropas patriotas dirigidas por el general San Martín habían ingresado a la ciudad de Lima el 10 de julio del año en mención. Las armas de la patria tenían bajo 
control el corazón realista de Sudamérica, desde donde se había sostenido una década de guerra contrarrevolucionaria. El editorial de la Gazeta Ministerial de Chile, titulado "Generosidad cívica" del 25 de agosto de 1821, indicó:

Por extraordinarios y prodigiosos que hayan sido los prósperos acontecimientos, que ha establecido el curso de nuestra revolución, ninguno tan glorioso ni de mayor importancia como el de la independencia del Perú. ${ }^{2}$ Él ha fijado nuestra emancipación política, haciendo desaparecer para siempre la vacilación, e inestabilidad en que fluctuábamos a pesar de nuestros sacrificios. ${ }^{3}$

Considerando el ímpetu emocional de las palabras enunciadas, este trabajo examina la celebración de la toma de Lima, símbolo de la consecución de la independencia del Perú, en las páginas de La Gazeta Ministerial de Chile, el órgano oficial del Gobierno de Bernardo O’Higgins. En 1821, dicho Gobierno ejemplificó el intenso esfuerzo emocional, sensorial y simbólico por cimentar una nueva realidad política: la posesión patriota del corazón realista de Sudamérica. A pesar de que la toma de Lima fue producto de una negociación política y no de una batalla en la ciudad que hiciera posible el ingreso del ejército patriota, el Gobierno de O'Higgins en Santiago de Chile divulgó este evento histórico como el mayor triunfo patriota conseguido en Sudamérica hasta ese momento. Las noticias de la toma de Lima produjo un ciclo celebratorio en Santiago de Chile en agosto de 1821. Este reveló el empleo de la metáfora familiar con la finalidad de lograr intensidad emocional, mientras los códigos sonoros y visuales desplegados por el poder buscaron impresionar y educar a la población sobre la irreversibilidad de la independencia de Chile.

2 Las cursivas son nuestras.

3 Generosidad cívica. Gazeta Ministerial de Chile, 25 de agosto de 1821. Archivo de don Bernardo O'Higgins (ABO). Academia Chilena de la Historia, 1963, tomo XV, p. 291. 


\section{बard}

En el acápite titulado "La celebración de la liberación de Lima y la resignificación de la derrota de Rancagua", se hace hincapié en el retorno glorioso de las banderas patriotas capturadas por los realistas en la batalla de Rancagua el 2 de octubre de 1814. San Martín remitió estos emblemas de Lima a Santiago. La segunda parte, "La celebración de la independencia del Perú y la sublimación heroica de Bernardo O'Higgins", presenta el rol fundamental de los múltiples rituales políticos y festejos públicos llevados a cabo en agosto de 1821, los cuales cumplieron el objetivo de consolidar y sedimentar el aura continental heroica del director supremo del Gobierno chileno. Se enfatiza la construcción de la coincidencia simbólica festejada el 20 de agosto de 1821: esta fecha celebraba la liberación de la ciudad de Lima por la acción de las armas del Ejército Libertador, el aniversario de la partida de la Expedición Libertadora, y el cumpleaños de O'Higgins. Así mismo, se observa la apropiación de la imagen de los incas por parte de O'Higgins y de otros actores políticos de Santiago, con la finalidad de exaltar sus figuras militares y políticas. La liberación de la ciudad de Lima se constituyó en un hito simbólico y político, al verificarse la inseparable vinculación entre ambas ciudades en el ocaso del dominio español en América.

En el análisis de la celebración de la independencia del Perú

220 en Santiago de Chile, se sigue la pauta teórica del clásico libro de David Kertzer, Ritual, politics \& power, (1989). A pesar del tiempo transcurrido desde su publicación, el estudio de Kertzer resulta clave para explicar la dimensión simbólica de la política y el potente poder de los rituales para proveer legitimidad, definir lealtades políticas, construir mitos políticos y crear una realidad política a través de la estructuración de percepciones sensoriales y la canalización de las emociones. Más aún, como Kertzer lo señaló, los rituales 
llevados a cabo durante procesos revolucionarios son los más intensos, pues los nuevos líderes tienen la tarea esencial de reemplazar el sistema político, las instituciones, los hábitos, el comportamiento social y la concepción del mundo de la población. Es decir, los rituales deben simbolizar el cambio político, legitimar una nueva realidad social, un nuevo orden, pero, al mismo tiempo, deben imponer estabilidad. Esta legitimación no está basada en el convencimiento razonado o en el pensamiento crítico de las nuevas estructuras de poder o de los diferentes grupos sociales. Por el contrario, los rituales - con la finalidad de ser exitosos- deben apelar a la persuasión visual de los símbolos, la seducción de las voces, la elaboración de un intenso clima emocional y la exaltación de los sentidos a través del desenvolvimiento de colores, gestos, movimientos. Estos elementos, a su vez, son potentes generadores de sentimientos. Para sustentar su poder, los líderes políticos estructuran una serie de rituales o comportamientos simbólicos que focalizan ciertos escenarios y determinados tiempos. El objetivo es claro: los individuos y colectivos participantes en ceremonias, fiestas y demás celebraciones deben experimentar una saturación emocional y sensorial, con la finalidad de conseguir su identificación política con los líderes políticos y sus respectivos proyectos (Kertzer, 1989, pp. 9, $10,40,85,99$ y 119$)$.

Esta perspectiva de Kertzer resulta pertinente para la presente investigación, ya que la guerra de independencia en Hispanoamérica no solo implicó una revolución política; también significó una larga y feroz guerra de símbolos, emblemas, alegorías, discursos y celebraciones (Lorandi, 2015). Los habitantes de las ciudades y los pueblos vivieron la constante movilización de ejércitos, lo cual, a su vez, supuso un masivo despliegue de símbolos y rituales, y la realización de celebraciones. Las ciudades de Lima y Santiago de Chile ejemplifican muy bien esta idea. De vivir en una permanente guerra de propaganda, ambas mutaron hacia la conformación de 
una fraternidad simbólica, tal como lo evidencia la prensa de la época (Morán, 2017). A inicios de 1821, ambas ciudades eran enemigas. Mientras que Lima era un bastión realista, Santiago ya tenía instalado un gobierno republicano. Sin embargo, al final de ese mismo año, ambas eran patriotas.

Este trabajo se ha nutrido también de las investigaciones del historiador argentino Pablo Ortemberg sobre las fiestas cívicas del Perú independiente. Su libro Rituales del poder en Lima (1732-1828): de la monarquía a la república explica la "refundación simbólica del ceremonial independentista" (Ortemberg, 2013a; Ortemberg, 2014). En forma minuciosa, Ortemberg ha presentado la negociación simbólica que conllevó a la proclamación de la independencia del Perú el 28 de julio de 1821. El autor considera al 28 de julio como "el primer ceremonial independiente" al convertirse "en el certificado de nacimiento del Estado peruano". Sin embargo, lo más importante del trabajo de Ortemberg es la perspectiva metodológica, pues establece un "diálogo" entre Lima y "las otras ciudades americanas como Buenos Aires y Santiago", ya que las fiestas cívicas del Perú independiente celebraban "una historia común todavía por escribirse" (Ortemberg, 2006, p. 250). Así mismo, resulta de mucha utilidad la perspectiva cronológica propuesta, al contextualizar los actos de los protagonistas, pero, sobre todo, al ubicar el momento simbólico, los rituales y los protagonistas individuales y colectivos en su contexto espacial y temporal. En este sentido, demuestra el protagonismo del ministro Bernardo Monteagudo tanto en instaurar regulaciones simbólicas como en realizar los rituales cívicos en la ciudad de Lima durante 1821 y 1822. Estas disposiciones y actos confirman que Monteagudo aplicó en Lima el patrón del ritual revolucionario implementado por chilenos y rioplatenses (Ortemberg, 2009). En un contexto de guerra inconclusa, el calendario festivo del protectorado estuvo marcado por las fiestas cívicas que recordaban victorias militares. En el Perú, se instituyó la conmemoración de 
los aniversarios de las batallas que habían logrado la independencia de Chile: la batalla de Chacabuco (12 de febrero) y la batalla de Maipú (5 de abril) (Ortemberg, 2013b). Así mismo, las publicaciones y narrativas en la prensa sobre las fiestas cívicas buscaban transformar la opinión pública, construir un nuevo momento fundacional, y consolidar la legitimación política y simbólica de los líderes militares patriotas y su proyecto político.

En relación con las investigaciones sobre el caso chileno, destaca Paulina Peralta, quien, en ; Chile tiene fiesta!: el origen del 18 de setiembre (1810-1837) (2007), analiza el decisivo rol que cumplieron instituciones, como el cabildo, y gobernantes, como Portales y Prieto, en consagrar el 18 de setiembre como la fiesta patria. En forma ilustrativa, Peralta presenta la poderosa presencia de la Revolución francesa en la elaboración del lenguaje simbólico republicano en Chile durante el Gobierno de Bernardo O’Higgins. Sin embargo, lo más interesante para el presente estudio es el rol de los agentes políticos conservadores en "sepultar" la conmemoración de la batalla de Chacabuco en 1817, la cual, a su vez, condujo a la proclama de la independencia de Chile en 1818. Una victoria militar quedó defenestrada del calendario patriótico chileno en las décadas posteriores a la independencia. La autora sugiere que esta eliminación de la memoria histórica de la nación respondía al temor de un regreso de Bernardo O'Higgins, quien vivía su exilio en la ciudad de Lima. El trabajo de Peralta está relacionado también con el análisis de la circulación de la obra de actores políticos, intelectuales y militares clave en la elaboración de los símbolos nacionales. Por ejemplo, la autora menciona el caso del santafecino Bernardo Vera y Pintado, autor del himno nacional e importante colaborador de O'Higgins (Peralta, 2007). ${ }^{4}$

4 El texto de Vallejos y Valdivia (2009) complementa la propuesta de Peralta. 
A nivel metodológico, este estudio busca superar el examen focalizado de las celebraciones, conmemoraciones, rituales, emblemas y fiestas cívicas desenvueltos en determinados centros urbanos. La guerra de independencia implicó la amplia movilización de ejércitos, quienes, en calidad de colectivos, debían ser motivados por alegorías, poesías, canciones, emblemas, proclamas, ya que debían estar dispuestos a morir por amor a la patria. Las autoridades de las ciudades o los líderes militares celebraban sus victorias o elevaban solemnes rogativas que recordaban y glorificaban el sacrifico de los soldados, lo cual transformaba el ritmo y el espacio urbanos. En este sentido, si bien los estudios por ámbitos urbanos ofrecen un universo rico de la dimensión simbólica de la guerra, se considera apropiado intentar realizar conexiones o comparaciones para detectar las oposiciones y/o complementariedades simbólicas entre ciudades. En este caso, en especial, las celebraciones en las ciudades de Lima y Santiago estuvieron íntimamente vinculadas, al entrelazarse las victorias y las derrotas, la sublimación de los líderes militares e, incluso, la apropiación de los ancestros heroicos.

\section{La celebración de la liberación de Lima y la resignifica- ción de la derrota de Rancagua}

En 1821, las ediciones extraordinarias del periódico oficial la Gazeta Ministerial de Chile ponen de manifiesto el papel de los líderes políticos, intelectuales y militares, quienes, para festejar la independencia del Perú, emplearon los productos culturales del nacionalismo, como la poesía, las canciones, y las celebraciones (Anderson, 1991, pp. 135, 62-63 y 141). El uso de la prensa como fuente primordial en el examen de las narrativas y contextos festivos nos vincula al ampliamente reconocido libro de Benedict Anderson (1991), el cual consagró el poderoso rol de los periódicos en la construcción de las comunidades imaginadas, al crear sentidos de pertenencia, lazos afectivos y experiencias tempo-espaciales. Ander- 
son señaló que los líderes criollos inventaron comunidades nacionales en su lucha por la independencia de España. Por ello, a principios del siglo XIX, la simbiosis entre el diario y la fundación de la nación es incuestionable (Anderson, 1991, pp. 62-63). En efecto, podemos considerar a la Gazeta Ministerial de Chile un monumento textual de la independencia del Perú. La circulación del periódico en Santiago, Lima y otras ciudades de Hispanoamérica trascendía la materialidad y fragilidad física del impreso y del momento de la publicación, e incluso adquirió una mayor durabilidad en el tiempo, de modo que superó a los monumentos materiales (Bezzola, et ál., 2009). ${ }^{5}$ En sus páginas, se lee la serie de actos celebratorios, proclamas, discursos, poemas, descripciones de festividades e, incluso, las aclamaciones.

El 13 de agosto de 1821, salvas de artillería y repiques de campanas comunicaron estruendosamente a los habitantes de la ciudad de Santiago de Chile el ingreso del Ejército Libertador a la ciudad de Lima, ocurrido el 10 de julio. ${ }^{6}$ Al día siguiente, el número extraordinario del 14 de agosto circuló con las siguientes ovaciones "VIVA LA PATRIA, VIVA LA NACION CHILENA, El Perú Libre". ${ }^{7}$ Estas palabras cargadas de sentimiento, pasión y alegría manifestaban el inmenso júbilo organizado y vivido en la capital chilena ante la consecución de la tan ansiada toma de Lima. El empleo de mayúsculas enunciaba y saludaba el más grandioso momento épico de las armas de la patria desde 1810. El Ejército Libertador, conducido por el general José de San Martín, y constituido

5 Los textos o monumentos verbales son más duraderos que los monumentos de piedra, tal como lo señalan los poetas desde la Antigüedad (Bezzola y Ochsner, 2009, p. 19). La traducción es nuestra.

6 Gazeta Ministerial Extraordinaria de Chile, 15 de agosto de 1821, tomo $\mathrm{XV}, A B O$, p. 255.

7 Gazeta Ministerial Extraordinaria de Chile, 14 de agosto de 1821, tomo $\mathrm{XV}, A B O$, p. 249. 
por chilenos y rioplatenses, había ocupado el corazón contrarrevolucionario de Sudamérica, Lima. Desde ahí, habían partido los ejércitos del Rey para sofocar y silenciar los centros insurgentes, como lo experimentó Chile en 1814. En cambio, en 1821, la situación cambió dramáticamente, al producirse la liberación de Lima. Bernardo O’Higgins, el director supremo de Chile y líder estratégico en la organización de la Expedición Libertadora, expresó emocionado en Santiago: "Al anunciar a los generosos pueblos de Chile la libertad dada a la capital del Perú por las armas victoriosas de la República mi corazón se agita [...] Poco importan que a mi nada me quede cuando la causa de la Libertad ha adquirido un Perú". ${ }^{8}$

¿Por qué tanta alegría y emoción en la capital chilena ante la liberación de Lima en julio de 1821? Este suceso militar y político significaba la culminación de un ansiado proyecto. A fines de 1818, la independencia de Chile iniciaba un proceso de consolidación, debido al memorable triunfo patriota en la batalla de Chacabuco, el 12 de febrero de 1817, la proclamación de la independencia de Chile, en 1818, y la instalación de un régimen republicano liderado por Bernardo O'Higgins, investido como director supremo. Culminando 1818, el periódico el Sol de Chile indicaba: la "hora de América ha sonado ya", pues "desde la majestuosa cima de los Andes" se anunciaba el fin del dominio español en América. No obstante, esta independencia estaba incompleta si la capital peruana continuaba controlada por las fuerzas realistas. El editorial recalcó la importancia estratégica de la toma de Lima, ya que esta decidía "la suerte de todos cuantos habitan desde el Cabo hasta el Istmo” y supondría la conclusión de la revolución. ${ }^{10}$ Se desprende que la captura militar de la capital

8 Gazeta Ministerial de Chile, "Circular del Excmo. señor Supremo Director a los pueblos", 25 de agosto de 1821, ABO, tomo XV, p. 296.

9 El Sol de Chile, 20 de noviembre de 1818, p. 10.

10 El Sol de Chile, 20 de noviembre de 1818, p. 10. 
del virreinato peruano por parte de las tropas patriotas era un hecho irrenunciable e ineludible, un objetivo que debía ser alcanzado a toda costa.

En efecto, el 20 de agosto de 1820, zarpó la Expedición Libertadora al Perú desde el puerto de Valparaíso bajo el mando del general San Martín. La elección del día de la partida de la estratégica empresa militar que buscaba ocupar la ciudad de Lima poseía una fuerte connotación simbólica. Ese día se celebraba el cumpleaños del máximo líder político y militar del Gobierno chileno, Bernardo O’ Higgins. El general William Miller, quien integraba la fuerza expedicionaria, estaba impresionado por la multitudinaria despedida ofrecida por los habitantes de la ciudad de Santiago y del puerto de Valparaíso. El pueblo, jubiloso, los "bendecía y animaba” (Miller, 1918, pp. 278-279). Se dirigían hacia el Perú, considerado la "trinchera del poder despótico de España en América". ${ }^{11}$ El envío de una expedición militar desde Chile hasta el Perú respondía al convencimiento estratégico de que solo la campaña marítima y el dominio del Pacífico podrían lograr la independencia del Perú. Con ello, se consolidaría la independencia de Chile y se conseguiría su reconocimiento internacional, especialmente por parte de las potencias extranjeras. $^{12}$

Las ediciones de la Gazeta Ministerial de Chile, al informar sobre el itinerario y accionar del Ejército Libertador del Perú, exaltaban su misión histórica con el lema "VIVA LA PATRIA". Las poesías por la despedida de la Expedición Libertadora identificaban a la "PATRIA amada", la cual había dado "una orden irrevocable" a los bravos guerreros. Ellos

11 Gazeta Ministerial de Chile, 17 de junio de 1820, ABO, tomo XIII, pp. 471-472.

12 Gazeta Ministerial de Chile, 18 de setiembre de 1819, ABO, tomo XIII, p. 110 . 
debían salvar al Perú liberándolo del yugo hispano. ${ }^{13}$ Esta era una patria alegórica, femenina, una madre que acompañaría a sus hijos en la gesta y por la cual ellos debían sacrificarse. ${ }^{14}$ La noticia del desembarcó en Paracas se publicó dos meses después de sucedido el acontecimiento, el 8 de noviembre de $1820 .{ }^{15} \mathrm{~A}$ fines de 1820 , las fuerzas patriotas calculaban que, en el lapso de "tres meses tremolará en Lima el estandarte de la libertad". ${ }^{16}$ Si bien los plazos no se cumplieron de acuerdo con las expectativas, las fuerzas de la patria lograron ocupar la ciudad de Lima el 10 de julio de 1821. El virrey José de la Serna abandonó la ciudad para no "perecer de hambre" o "morir sin gloria". ${ }^{17}$ Este vacío de poder significó la materialización de un hecho político y militar inimaginable en casi 300 años de dominio español. La "Fidelísima Ciudad de los Reyes" pasó a ser designada "Heroica y Libre". ${ }^{18}$

Un contundente despliegue sonoro comunicó a la población de la ciudad de Santiago el ingreso de las tropas lideradas por

13 Despedida de las chilenas al Egercito Libertador del Perú (1820) y Contestacion del Egercito Libertador del Peru a la despedida de las chilenas (1820).

14 Sobre el uso de las alegorías femeninas, véase Sánchez (2013, pp. 213236). Para el caso chileno en particular, véase Cruz (1991). Para una perspectiva sobre Hispanoamérica, véase Robira (2016).

15 "Noticias de la expedición Libertadora del Perú", Gazeta Ministerial Extraordinaria de Chile (13), 8 de noviembre de 1820, $A B O$, tomo XIV, pp. 139-140.

16 Gazeta Ministerial Extraordinaria de Chile, 14 de agosto de 1821, ABO, tomo XV, p. 253.

17 Gazeta Ministerial Extraordinaria de Chile, 14 de agosto de 1821, ABO, tomo XV, p. 253. Sobre este aspecto crucial para entender la estrategia del bloqueo, y por qué San Martín no entró a sangre y fuego a la ciudad de Lima, véase Sánchez (2001).

18 Arnaldo Mera (2005) presenta un detallado trabajo de investigación que revela la intensidad del momento histórico que se vivió en la ciudad de Lima en 1821. 
San Martín a la ciudad de Lima. El 13 de agosto de 1821, una "salva de artillería y repiques generales de campanas" anunciaron un evento excepcional y único. La población se reunió en el Palacio Directoral para la lectura de las noticias procedentes de Lima. El mencionado día, los festejos continuaron hasta el amanecer del día 14, caracterizado por el "estruendo de infinitos cohetes" mientras que "la salva de la artillería concluyó el anochecer". La intensidad sonora estuvo acompañada por la iluminación de la ciudad durante la noche, mientras "las músicas militares anduvieron por las calles acompañando el universal júbilo, y todo el pueblo se ocupó en aquel espacio en saraos y bailes y canciones nacionales". ${ }^{19}$ Esta trilogía de espectacularidad compuesta por cańonazos, campanas y bandas militares ejemplificaban el "código acústico" heredado del innovador programa de reformas borbónicas en el ámbito militar y urbano (Valenzuela, 2014, pp. 155-156). En 1821, estos artefactos diseñados por la monarquía española estaban siendo resignificados, porque ahora celebraban la ocupación de la ciudad más importante del imperio español en Sudamérica por fuerzas insurgentes, identificados, también, con la patria.

Con la finalidad de comunicar y emocionar a la población de la ciudad de Santiago, la edición de la Gazeta Ministerial de Chile del 14 de agosto rompió la monotonía visual de su primera plana para capturar la atención de los electores y mostró en el encabezado los excepcionales vítores: "VIVA LA PATRIA, VIVA LA NACION CHILENA, El Peru Libre". Esta edición posee un enorme simbolismo. Los bandos, las proclamas, los dirigentes militares, los impresos y las voces hacían públicos los sucesos más trascendentes de las campañas militares, pero no solamente con el objetivo de comunicar, sino, sobre todo, de exaltar la moral. El tono enérgico al

19 Gazeta Ministerial Extraordinaria de Chile, 15 de agosto de 1821, ABO, tomo XV, pp. 255-256. 
enunciar y vocalizar palabras clave buscaba activar, motivar entre la población la constante renovación de los ideales de libertad e independencia (Davio, 2015, 2017 y 2019, y De Gori, 2020). Sin embargo, en esta ocasión, las aclamaciones mencionadas marcaban un momento de ruptura. Era la primera vez que esta trilogía de gritos se usaba para celebrar una victoria. Se considera, por lo tanto, que estos vítores mostraban la contundencia de la irreversibilidad de la independencia de Chile. Al mismo tiempo, estas aclamaciones se constituyen en marcadores temporales al delimitar el ciclo celebratorio de la liberación de Lima, entendida y publicitada como la independencia del Perú, ciclo que tuvo lugar entre el 14 y el 29 de agosto.

De forma significativa, la edición extraordinaria del 15 de agosto describía las aclamaciones de la población, tales como "VIVAN NUESTROS HERMANOS LOS PERUANOS", así como también se aclamaba a San Martín y a O’Higgins; esto revela el deseo por construir una "filiación concreta y tangible" y la fraternidad de una comunidad política. ${ }^{20}$ Cabe destacar que dichas expresiones no eran producto de la emoción del momento. En junio de 1820, el Cabildo de Santiago, cuando anunció la partida de la Expedición Libertadora hacia el Perú, identificaba a los chilenos como los "hijos de la libertad", en virtud de haber derrotado a los españoles en Maipú el 5 de abril de 1818, mientras que "los pueblos hermanos del Perú" gemían "bajo el yugo de un despotismo". ${ }^{21}$

Estas expresiones filiales revelan el uso de la metáfora familiar en consonancia con la influencia de la Revolución francesa para denotar el proceso simbólico político de reemplazo de la familia política del orden colonial -basada en la autoridad paternal del rey- hacia otra comunidad política basada en

20 Sobre este aspecto, véase el sugerente artículo de Jarak (2013).

21 Gazeta Ministerial de Chile, 17 de junio de 1820, (49), ABO, tomo XIII, p. 471. 
la exaltación, construcción y movilización de la fraternidad como principio político - una comunidad política masculina, que, a su vez, ya estaba experimentado la proliferación de nuevas figuras paternales, los nuevos padres de la patria (Hunt, 1992, pp. XIII y 9-10)-. El énfasis en la fraternidad revolucionaria se convirtió en el pilar de la idea republicana de virtud. Sin embargo, esta fraternidad fue asumida como una virtud pública y viril. El retorno de los patriotas después del triunfo sobre los realistas en Chacabuco en febrero de 1817 bajo el liderazgo de O'Higgins robusteció el aura simbólica de los líderes militares y marcó el inicio el período de la Patria Nueva (Valenzuela, 2014, p. 168).

En estrecha vinculación con los triunfos y derrotas militares, las ciudades se transformaban en escenarios de batallas simbólicas. Así, el control patriota de la ciudad de Lima hizo posible la reivindicación simbólica de la traumática derrota patriota en la batalla de Rancagua, acontecida el 2 de octubre de 1814, que puso fin al período de la Patria Vieja e hizo posible la "Reconquista". En 1814, O’Higgins fue derrotado. En cambio, en 1821, anunciaba la liberación de Lima en estrecha conexión con el retorno de las banderas patriotas capturadas por las tropas realistas en Rancagua. O’Higgins señaló:

El Ejercito Libertador del Perú ha entrado sin oposición a la antigua capital de los Reyes que desde Lima, abandonada a discreción a la de nuestras armas por la fuga del ultimo usurpador, que es perseguido activamente. [...] Las banderas que en Rancagua arrebato la fortuna de la mano de los valientes, han sido recuperadas del templo de Santo Domingo de Lima, donde servían de trofeo al orgullo de los tiranos antes que de homenaje al Dios de la libertad."22

22 Gazeta Ministerial de Chile, 25 de agosto de 1821, $A B O$, tomo XV, p. 297. Las cursivas son nuestras. 
En efecto, el 14 de agosto, a las 10 a. m., "entraron las banderas de Rancagua recobradas en Lima". Este retorno triunfal a la patria de origen fue solemnizado por una salva de 100 cańonazos y repiques generales de campanas. La jornada celebratoria concluyó con un tedeum en la catedral a las 5 de la tarde. ${ }^{23}$ Este ritual de rigurosa solemnidad superaba largamente la tradición monárquica borbónica. Estaba estipulado que los más importantes eventos de la monarquía española, como las juras reales, fueran saludados por salvas de 21 cañonazos. Inclusive, en 1821, lo dispuesto para la conmemoración del triunfo en Chacabuco superó en contundencia la tradición: se ordenaron tres días de fiesta y, en el momento sublime del 12 de febrero, a las 9 a. m., cuando se llevó a cabo el traslado del estandarte, se ordenó la ejecución de "salva triple de artillería". ${ }^{24} \mathrm{El}$ hecho mismo de publicar el número de cañonazos buscaba perpetuar este momento glorioso, el cual formaba parte de la creación de una nueva realidad política, militar y de una nueva memoria histórica (Ortemberg, 2009, p. 69). Este ímpetu sonoro buscaba erradicar la humillación y afrenta experimentadas por las banderas patriotas capturadas por las fuerzas realistas después de la derrota en la batalla de Rancagua. Es decir, este ritual permitía celebrar la victoria y, al mismo tiempo, recordar a quienes murieron por la patria. Tenía la capacidad de impresionar, de agitar, pero también de cohesionar a los participantes, quienes fraternizaban por sentimientos de unión. Habían experimentado el dolor; ahora, compartían sentimientos de entusiasmo (Sánchez, 2008, pp. 47 y 53). La liberación de Lima había cambiado la conmemoración de la derrota.

El mismo 14 de agosto, "esas insignias de la bravura chilena" fueron objeto de un proceso de descontaminación simbó-

23 Gazeta Ministerial Extraordinaria de Chile, 15 de agosto de 1821, ABO, tomo XV, p. 256.

24 Gazeta Ministerial de Chile. "Doce de Febrero", 17 de febrero de 1821, $A B O$, tomo XV, p. 33. 
lica. La población participó de un cortejo brillante, el cual acompañó el desplazamiento de tan sagrados símbolos. Lo más significativo de este ritual se observó cuando estas "fueron pasadas en triunfo con toda la música marcial y colocadas en los balcones del palacio Directorial a la obstentación pública". ${ }^{25}$ Las banderas encarnan a la patria y, en calidad de artefacto sublime, poseían un gran poder sacralizador de los espacios y de los tiempos de celebración. El retorno de estas banderas significaba que los soldados de la patria habían "extirpado" el "monstruoso" poder realista. En este proceso de purificación simbólica, destaca el protagonismo de la música militar. Esta contribuía eficazmente a inscribir las banderas recuperadas en los lugares públicos, al profundizar el amor por la patria y la pertenencia a esta, mientras que reforzaba los lazos de unión entre sus miembros. La actuación de la música militar era vital. Esta no solo cumplía una función de saludar el retorno de las banderas de forma protocolar. Sobre todo, la música militar cumplió la función de reincorporarlas o reintegrarlas a la patria, y eliminar la marca contaminante de haber estado prisioneras en un recinto sagrado, pero en una ciudad enemiga, hasta ese momento.

Como parte de las celebraciones de la liberación de Lima, se produjo la resignificación de la derrota de Rancagua en la ciudad de Santiago de Chile, lo cual a su vez contribuyó a reforzar el poder sustentado en ese momento en la persona de O'Higgins. Las banderas recuperadas fueron ubicadas de modo transitorio en el lugar más importante de la ciudad, el Palacio Directoral. Indudablemente, el Gobierno buscaba impresionar, conmover a los habitantes de la ciudad y logró impacto visual en aquellos. El Palacio Directoral se convertía en un sitio de memoria, de resignificación de la derrota, ahora transformada en victoria. Al mismo tiempo, esta admira-

25 Gazeta Ministerial de Chile, 25 de agosto de 1821, ABO, tomo XV, p. 298. 
ción visual buscaba establecer vínculos de afectividad directa entre O'Higgins y la población. ${ }^{26} \mathrm{La}$ bandera encarnaba a la patria, Chile, esta vez triunfante, la cual había "tenido poder para llevar sus armas al Perú con tanta gloria que ya puede contarse con la agregación de esa numerosa familia a la causa americana". ${ }^{27}$

Este énfasis en la sacralización de las banderas recuperadas se entiende por lo acontecido en 1814, hecho que ha sido identificado por Ossa Santa Cruz, como el "más turbulento del primer período de la revolución chilena" (Ossa, 2016a, p. 233). De acuerdo con este autor, hasta mediados del mencionado ańo, el "principal enemigo de los insurgentes chilenos no era el rey de España" (Ossa, 2016a, p. 234), sino el virrey del Perú, José Fernando de Abascal. El deseo de ruptura con España se concretó a partir de la derrota en Rancagua (ubicada a 87 kilómetros al sur de Santiago). Abascal envió un ejército de 600 hombres al mando del coronel Osorio, el cual derrotó a las fuerzas comandadas por Bernardo O’Higgins. Este revés puso término al período denominado la Patria Vieja. O’Higgins marchó al exilio hacia Mendoza. Pocos días después de la derrota, ocurrida el 2 de octubre, las tropas realistas retomaban el control de Santiago; ante ello, se procedió al embanderamiento realista de la ciudad, a lo que se agregaron los tradicionales repiques de campanas (Ossa, 2016a, pp. 235 y 251). Sin embargo, lo más traumático sucedió en la ciudad de Lima. Jaime Valenzuela establece la elaborada y cuidadosa deslegitimación, desacralización y humillación pública de las 9 banderas capturadas en Rancagua a los patriotas. En un acto impresionante nunca observado, se pa-

26 Esta interpretación está inspirada en los capítulos 4 y 5 de Jelin (2019), y en la introducción de Jelin y Langland (2003, p. 4).

27 "Contestacion del Senor Enviado de Chile cerca del Gobierno de Buenos Ayres al Diputado de SMF”. Buenos Ayres, agosto 14 de 1821. Gazeta Ministerial de Chile, 29 de setiembre de 1821, ABO, tomo XV, p. 359. 
tentizaba el poder contrainsurgente de Abascal. Las banderas fueron colocadas en el suelo, y la carroza del representante del monarca español en el Perú pasó sobre ellas. Posteriormente, los maltratados pendones que servían para marcar el cautiverio de la ciudad de Santiago fueron colocados en la iglesia de Santo Domingo (Valenzuela, 2009, p. 289).

La liberación de Lima resignificó la conmemoración del desastre de Rancagua. El propio O’Higgins señaló que, sin la toma de Lima del 10 de julio de 1821, esta hubiera continuado siendo recodada como "día de sangre y de gloria" ${ }^{28}$ En 1817, los patriotas conmemoraron el aniversario de Rancagua y a sus mártires con un "silencio majestuoso" y "luto general”. Sobre todo, el ejército debió guardar luto por tres días (Osorio y Guerrero, 2014, p. 181). La rogativa pública del 2 de octubre de 1817, en recuerdo de la "fatal jornada de Rancagua y de la época más funesta de Chile" buscaba infundir "un odio a la horrible dominación española" e inspirar "el amor a la Patria". ${ }^{29}$ Con la realización de esta conmemoración, los patriotas demostraban que la patria había retornado triunfante. La victoria de Chacabuco hacía posible su recuerdo público, pero era la liberación de la ciudad de Lima la que había vengado el sacrificio de los 400 mártires y la resistencia liderada por O’Higgins, quien combatió durante 36 horas el ataque realista (Osorio, 2014, pp. 177 y 181). En cambio, en 1821, como el mismo comandante general de armas José Manuel Borgoño en una comunicación desde Lima le expresaba a O'Higgins: "La restauración de estos trofeos es un motivo de júbilo para los amantes de la libertad, pero si se considera

28 Gazeta Ministerial de Chile, 25 de agosto de 1821, $A B O$, tomo XV, p. 298.

29 "Quaderno Libro Copiador de oficios de esta Intendencia general de Santiago. Año de 1817” (45), p. 29 (anverso). Archivo Nacional. Intendencia de Santiago, vol. 1, 1817-1829, citado en León y Alegría (2008, p. 116). 
que han sido tomadas en el asilo sagrado en que los tiranos creyeron perpetuarlos, debe estimarse esta importante adquisición como una prueba del irresistible poder de nuestra justa causa, y de la debilidad de nuestros enemigos". ${ }^{30}$

En el séptimo aniversario de la "horrorosa catástrofe" del 2 de octubre de 1814, el Supremo Gobierno de la República -tal como lo proclamó Bernardo O’Higgins- había concretado el deseo de "cambiar un cuadro tan lúgubre en una escena de entusiasmo y placer cívico" ${ }^{31}$ Lima estaba ocupada por fuerzas de la patria. Más allá de la connotación de amor a la patria y recuerdo de los mártires que murieron por ella, el retorno purificado de las banderas de Rancagua demostraba que la independencia de Chile era un proceso irreversible. En contraste, la toma de Lima inscribía a la capital peruana en una guerra continental que se prolongaría hasta 1826.

\section{La celebración de la independencia del Perú y la sublima- ción heroica de Bernardo O’Higgins}

Kertzer enfatiza el papel esencial que cumplen los ritos de poder al desplegar símbolos que permiten reemplazar sistemas políticos. Como la nación es una entidad abstracta, se hace necesario emplear símbolos con cualidades palpables, perceptibles sensorialmente. Para ello, se deben crear imágenes que la personifiquen. Los rituales colectivos son los más efectivos, porque cumplen con la función de envolver emocionalmente a los grupos sociales. Así mismo, las celebracio-

30 Gazeta Ministerial Extraordinaria de Chile, 14 de agosto de 1821, ABO, tomo XV, pp. 251-252. Las cursivas son nuestras.

31 Gazeta Ministerial de Chile, "RANCAGUA. Aniversario de 2 de octubre de 1814", 20 de octubre de 1821, $A B O$, tomo XV, p. 392. Las banderas fueron escoltadas hasta la misma ciudad de Rancagua donde arribaron el 30 de setiembre del año en mención. 
nes masivas se convierten en potentes vehículos de legitimación de la autoridad, la exhibición de la fortaleza política del líder, tendiente a su glorificación. Con frecuencia, los ritos de construcción de una nueva nación son utilizados para oficializar la figura heroica de un líder (Kertzer, 1989, pp. 9-10, 99, 119 y 124).

La celebración de la independencia del Perú, identificada con la liberación de Lima, revela el esfuerzo por robustecer y expandir el proceso de heroización de O’Higgins. El 20 de agosto, cumpleaños de Bernardo O'Higgins, fue transformado en "día memorable". En esta fecha de 1821, se celebró la "coincidencia" del aniversario de la partida de la Expedición Libertadora, el cumpleaños del director supremo, a lo que se agregaba la "lucida pompa" por la "libertad de la capital de los Incas". ${ }^{32}$ El Ayuntamiento de Santiago reconoce que "la gloria de que se ha cubierto V. E. cuando las armas de la nación que preside han ocupado la capital del Perú y coronado á la América con su independencia". ${ }^{33}$ Su éxito militar lo convertía en una figura heroica continental. Tal como lo señaló el autor del himno nacional, el santafecino Bernardo Vera:

¿Con qué el golpe del último tirano

Que va a consolidar la Independencia

Estaba reservada a Vuexelencia,

$\mathrm{Al}$ grande hijo del suelo americano? ${ }^{34}$

32 Gazeta Ministerial Extraordinaria de Chile, 21 de agosto de 1821, ABO, tomo XV, p. 275.

33 Gazeta Ministerial Extraordinaria de Chile, 21 de agosto de 1821, ABO, tomo XV, p. 281.

34 Gazeta Ministerial Extraordinaria de Chile, 23 de agosto de 1821, ABO, tomo XV, p. 288. 
Indudablemente, la narrativa patriótica buscó patentizar el poder regenerador de O' Higgins, el cual trascendería el tiempo al convertirse en modelo virtuoso para las futuras generaciones. Estas felicitaciones y reconocimientos para engrandecer a O'Higgins encajan con la propuesta de Patrick Hogan, quien establece que los padres fundadores, al ser recubiertos de un aura heroica, ejemplifican la paternidad política encarnada por líderes nacionales reconocidos como los padres de la nación. Esta identificación legitima la imposición de una relación jerárquica entre el gobernante y los gobernados tanto a nivel simbólico como político. Los gobernados, asumidos como los hijos de la nación, deben acatar las decisiones de las autoridades políticas. En lo emocional, identificar a la nación como familia activa el respeto y el amor filial hacia los líderes nacionales (Hogan, 2009, p. 132).

Con la finalidad de celebrar la independencia del Perú, el miércoles 22 de agosto se organizó en el Palacio Directoral un magnifico sarao, un baile elegante. En dicho evento, O’Higgins sublimó aún más su figura al llevar a cabo la movilización emocional del ancestro. Bernardo O'Higgins ofreció un brindis en el que incorporó y recuperó a los incas. Señaló: "A la independencia de la antigua y famosa Patria de los Incas. A los gloriosos guerreros sus libertadores. A su inmortal caudillo, el General San Martín”. ${ }^{35}$ Esta expresión de O’Higgins comprueba su conexión con el incaísmo que identificó al "patriotismo criollo emancipador" y que se manifestó a través de textos conmemorativos, proclamas, canciones, poesía e himnos tal como lo patentizó la prensa (Díaz-Caballero, 2005, p. 85). ${ }^{36}$ En momentos de transición, como en Chile de 1821, los rituales oficializaron la invención de una nueva tradición,

35 Gazeta Ministerial Extraordinaria de Chile, 25 de agosto de 1821, ABO, tomo XV, p. 293.

36 Véanse también los trabajos de Striker (2016), Rípodas (1993) y Berdini (2016). 
(Hobsbawn, 1983) que sublimó la figura heroica, militar y masculina de Bernardo O'Higgins al construirse una vinculación atávica entre él y la liberación de Lima.

Debe recordarse que este brindis por los incas durante la celebración de su cumpleaños en 1821 y en un contexto conmemorativo que vinculaba a las ciudades de Lima y Santiago continuaba la apropiación del pasado incaico ya realizada en una ocasión anterior. En setiembre de 1819, el director supremo de Chile, Bernardo O'Higgins, lanzó una proclama a los "naturales del Perú", en la cual anunciaba la presencia militar procedente del sur y enfatizaba la fraternidad política que tanto unía al Perú y Chile. En esta proclama, O’Higgins identificaba a los "naturales del Perú" como hijos de "Manco Cápac, Yupanqui y Pachacútec", mientras presentaba a los miembros de la Escuadra como los "hermanos de Chile", quienes estaban dispuestos a sacrificarse con la finalidad de liberarlos. ${ }^{37} \mathrm{O}$ ' Higgins demostraba la cuidadosa selección de gobernantes incas, al mencionar al fundador mítico del Imperio incaico, Manco Cápac, y al transformador Pachacútec. Con la finalidad de unificar-cohesionar-, esta proclama, inclusive, fue traducida al quechua.

En el caso del brindis señalado, es preciso observar que O'Higgins identifica a la ciudad de Lima como la patria de los incas. Indudablemente, el líder militar buscaba cohesionar un proyecto político del presente, el nacimiento de un nuevo Estado. Sin embargo, también respondía a su formación intelectual en la ciudad de Lima a fines del siglo XVIII. Para O'Higgins, los incas, sus descendientes y sus monumentos arquitectónicos eran personajes y espacios cercanos. Benjamín Vicuña Mackena señaló la amistad de O'Higgins con un

37 Gazeta Ministerial de Chile, 4 de Setiembre de 1819, ABO, tomo XIII, pp. 103-105. Se señala en el documento que esta proclama fue traducida al quechua. 
cacique de Chilca, quien firmaba como Juan Nepomucemo Manco Inca, a quien conoció mientras estudiaba en el Colegio Príncipe (Vicuña, 1882, p. 34). Así mismo, tal como lo ha destacado Scarlett O'Phelan, al estudiar en el Convictorio de San Carlos, O’Higgins perteneció a la generación de criollos que lideró la revolución de la independencia (O’Phelan, 2013). Entre sus maestros, figuraban prominentes intelectuales, quienes publicaban en el Mercurio Peruano. A fines del siglo XVIII, Lima experimentaba la proliferación de la prensa ilustrada, y periódicos como el Mercurio Peruano y el Diario de Lima exaltaban a los monumentos del pasado incaico. Los sitios arqueológicos nutrieron el imaginario criollo, el cual reivindicó a los incas y a sus ruinas, y los rescató del olvido (Rosas, 2002 y 2005; y Rojas, 2017).

En 1821, identificar a Lima como patria de los incas significaba una potente transfiguración simbólica de la ciudad más realista de Sudamérica. Esta expresión era una forma sublime de legitimar la causa patriota, y enaltecer la Expedición Libertadora y, por supuesto, una vez más, al mismo O’Higgins. En calidad de ancestros heroicos, los incas contribuían a reforzar la dimensión simbólica de la liberación de Lima. La carta celebratoria de los miembros de la Sala Capitular de Concepción, en la que felicitaban a O’Higgins por la noticia de la rendición de las fortalezas del Callao, muestra su agradecimiento porque los ha liberado de la "madrastra de España”. En esta comunicación, este colectivo masculino enfatizaba el hecho de que tanto chilenos como peruanos iban a reconocer y recordar a O’Higgins como "el héroe [...] que redimió a nuestros padres de la más pesada y afrentosa servidumbre" ${ }^{38}$ Por lo tanto, la apropiación realizada por el

38 Gazeta Ministerial de Chile, 15 de diciembre de 1821, ABO, tomo XXIX. En este punto, se debe mencionar que otras ciudades de Chile, como Valparaíso, Talca y Concepción, también llevaron a cabo celebraciones por la independencia del Perú. 
propio O' Higgins, y las felicitaciones y otras comunicaciones que estrechaban la ligazón entre este y los incas confirman lo señalado por Rebecca Earle (2007). Esta historiadora demostró la apropiación política del pasado ancestral por parte de las élites criollas e insurgentes con la expresa finalidad de hacer propaganda y legitimar la guerra contra la monarquía espańola. La retórica insurgente rescató a aztecas, incas y araucanos, y los presentó como los ancestros metafóricos que la guerra de independencia debía resarcir históricamente. Es decir, se diseñó y forjó una genealogía insurgente, basada en la vinculación filial entre el presente y el pasado. Siguiendo la argumentación de Earle, O’Higgins ejemplificaría cómo el discurso criollo revolucionario empleó la metáfora familiar, al identificarse como los hijos políticos y simbólicos de los héroes indígenas, quienes habían sido sojuzgados durante la conquista española del siglo XVI (Earle, 2007, pp. 29 y 37). Se desprende, por lo tanto, que O'Higgins -transformado en padre protector - había liberado a chilenos y peruanos de Espańa, la cual es presentada como madrastra.

La celebración de la independencia del Perú también demuestra la "renovación simbólica" y la "reafirmación de las lealtades políticas" (Pico, 2012, p. 177). Es un caso concreto, el 28 de agosto, se llevó a cabo la "Función cívica del cuerpo de Infantes de la Patria”. Este se componía por afrodescendientes, tanto libres como libertos. Sobre ellos, la Gazeta señaló: "Nadie los ha excedido en las demostraciones de alegría por los progresos, de la Patria en el Perú, y en especial por la libertad de su capital Lima". ${ }^{39}$ Los integrantes de los Infantes de la Patria conformaban las bandas de música militar, se encontraban en constante periplo, y, por supuesto, tenían un papel protagónico durante las batallas o durante las celebraciones políticas. Su música levantaba la moral de

39 Gazeta Ministerial de Chile, 8 de setiembre de 1821, $A B O$, tomo XV, p. 316 , 
los soldados, alegraba a la población al ingreso del ejército o durante las ascensiones al poder (Contreras, 2011). Este protagonismo se entiende por el impulso que el ejército de los Andes le dio a la presencia de batallones de música compuestos por afrodescendientes en las celebraciones oficiales, en el campo de batalla, "pues el pueblo al oír aquella música [...] creía estar en la gloria" (Zapiola, 1974, p. 37, citado por Madrid, 2018, p. 78).

En este sarao, que se llevó a cabo desde las tres de la tarde del 28 de agosto hasta las 7 de la mañana del día siguiente en la casa del senador Juan Agustín Alcalde, O’Higgins pronunció el brindis "Por la independencia del Perú, porque se consolide su libertad [...]" en un ambiente en el que estaban colocados los retratos de San Martín y de él mismo. ${ }^{40}$ Esta conjugación entre lo visual y lo sonoro sintetiza el binomio de "celebrar y gobernar", sugerido por Munilla Lacasa en su espléndido libro Celebrar y gobernar. Un estudio de las fiestas civicas en Buenos Aires, 1810-1835 (2013). A través de la palabra y de las imágenes, se buscaba consolidar el poder político. O'Higgins estaba presente y representado al mismo tiempo, lo que reflejaba la transformación simbólica producida por la guerra. La patria tenía nuevos padres, los héroes militares que la habían liberado. El retrato del rey "expresión material del concepto de monarquía" era parte del pasado (Majluf, 2013, p. 85).

Siguiendo la propuesta de Carlota Casalino, se considera que el proceso de sublimación de O'Higgins, llevado a cabo durante las celebraciones de la independencia del Perú, lo transformó en padre fundador, pero no solo de Chile, sino también del Perú, ya que se configuró una comunidad politica fraterna entre ambas entidades. Un elemento clave en

40 Gazeta Ministerial de Chile, 8 de setiembre de 1821, ABO, tomo XV, pp. 317-318. 
esta sublimación lo proporcionó la pedagogía cívica, de los retratos y de la concentración simbólica de su cumpleańos. Así mismo, al centro de la construcción de esta comunidad fraterna, la figura de O’Higgins buscó incrementar la legitimad política de su Gobierno. La apropiación de los incas mostraba la "transfiguración de un personaje carismático y paradigmático en ancestro heroico fundador" de una nueva era (Casalino, 2008, pp. 7-8). En efecto, O'Higgins fue condecorado como fundador de la Orden del Sol. En 1822, el Perú, administrado por San Martín, lo reconocía como su libertador. La Gazeta Ministerial de Chile destacó que dicho reconocimiento revelaba la "íntima unión de los dos Gobiernos, en orden á concluir gloriosamente la guerra de independencia”. ${ }^{41}$

\section{Conclusión}

La celebración de la liberación de Lima significó una intensa movilización emocional y simbólica en la ciudad de Santiago de Chile en 1821. En lo emocional, líderes como Bernardo O’Higgins apelaron al empleo de la metáfora de la familia. Él fue identificado como padre heroico de la naciente nación chilena. En lo sensorial, se observó la trascendencia del despliegue sonoro y visual. Así mismo, la toma de Lima cambió dramáticamente la conmemoración de la batalla de Rancagua. El ciclo celebratorio desarrollado y publicitado denotó la resignificación de la derrota militar y su posterior transformación en victoria. En calidad de director supremo, O’Higgins celebró el ingreso en Lima, el cual fue amplificado y publicitado como la consecución de la independencia del Perú. Las piezas poéticas a San Martín en la Gazeta Ministerial de Chile lo reconocían como "VENCEDOR DE CHACABUCO Y MAIPO" y "REDENTOR DE LIMA". ${ }^{42}$

41 Gazeta Ministerial de Chile, 1 de junio de 1822, ABO, tomo XV, p. 91.

42 Gazeta Ministerial de Chile, 15 de agosto de 1821, $A B O$, tomo XXX, p. 255. 
La genealogía revelada por estas victorias militares es contundente. Si Chacabuco había hecho posible la recuperación de la ciudad de Santiago para las fuerzas patriotas, la toma de Lima había liberado a Chile de la Lima realista y, también, de España. Para Chile, el júbilo demostrado sellaba la irreversibilidad de la independencia conseguida, declarada e institucionalizada política y simbólicamente. Por lo tanto, la proclamación de San Martín el 28 de julio tuvo implicaciones más transcendentales para Chile que para el Perú. No obstante, si bien para el caso del Perú la liberación de Lima conllevó el nacimiento legal del Estado peruano, la guerra de la independencia continuaría hasta 1826. El Perú tenía una independencia de España proclamada, pero todavía no conseguida. Como en el caso de Chile, habría que esperar la contundencia de las victorias militares.

Recibido: 08 de agosto de 2020

Aprobado: 29 de noviembre de 2020

\section{Fuentes de archivo}

\section{Archivo de don Bernardo O'Higgins (ABO)}

- Tomo XIII. Instituto Geográfico Militar, 1959.

- Tomo XIV. Editorial Universidad Católica, 1962.

- Tomo XV. Academia Chilena de la Historia; Editorial Universidad Católica, 1963.

- Tomo XXIX. Academia Chilena de la Historia; Editorial Universidad Católica, 1963.

- Tomo XXX. Academia Chilena de la Historia; Editorial Universidad Católica, 1963. 


\section{Bibliografía}

Alegría, C. (2008)

¡Se acabó la fiesta! (Tesina para optar el grado de licenciada en Historia). Universidad de Chile, Facultad de Filosofía y Letras, Departamento de Ciencias Históricas, Santiago de Chile.

Ávalos, A. M. (2005)

"Cuando la patria llegó a la capital: el miedo ante el advenimiento de la independencia, 1820-1821". En C. Rosas (Ed.), El miedo en el Perú. Siglos XVI al XX (pp. 185-231). Pontificia Universidad Católica del Perú.

Anderson, B.

Imagined Communities. Reflections on the Origin and Spread of Nationalism. Verso.

Berdini, J. A.

(2016) "Santos reyes. Virtuosos incas. Antiguos tiranos: imagen de la monarquía en la homilética sagrada rioplatense (siglos XVIII-XIX)". Folia Histórica del Nordeste, (27), 127-148.

Bezzola, L. y Ochsner, A. (Eds.).

Moment to Monument: The Making and Unmaking of Cultural Significance. Transcript \& Transaction Publishers.

Bridikhina, E.

(2010) "La propaganda política y creación del nuevo lenguaje festivo en los primeros ańos de la república de Bolivia: rupturas y continuidades". Espacio Tiempo y Forma. Serie V, Historia Contemporánea, (22).

Casalino, C.

(2008) Los héroes patrios y la construcción del Estado-nación en el Perú (siglos XIX y XX). (Tesis para optar el grado 
de doctor). Facultad de Ciencias Sociales, Universidad Nacional Mayor San Marcos, Lima.

Conde, J. y Monsalvo, E.

(2010) "La construcción del orden político y las celebraciones republicanas en la Nueva Granada (Colombia, 1810-1832)". Revista Historia y Espacio, 6 (35), 7196.

Contestacion del Egercito Libertador del Peru a la despedida de las chilenas.

s. e. https://archive.org/details/contestaciondele00ejrc/page/2/mode/2up

Contreras, $\mathrm{H}$.

(2011) "Artesanos mulatos y soldados beneméritos: el batallón de Infantes de la Patria en la guerra de independencia de Chile, 1795-1820". Historia (Santiago), 44 (1), 51-89.

Cruz O. I.

"Diosas atribuladas: alegorías cívicas, caricatura y política en Chile durante el siglo XIX". Historia, 30, 127-171.

Davio, $\mathrm{M}$.

(2019)

"Discursos de los (con)vencidos: Abascal, Pezuela y De la Serna frente a la guerra en Charcas (18091825)". Revista del Instituto Riva Agüero, 4 (1), $285-$ 336. http://revistas.pucp.edu.pe/index.php/revistaira/article/view/20501/20401

Davio, M.

(2017)

"Construir la revolución desde la opinión: proclamas, bandos y exhortaciones durante la guerra en el Alto Perú (1810-1814)". Nuevo Mundo Mundos Nuevos. http://nuevomundo.revues.org/71268 
Davio, M.

(2015) "Con la espada y la palabra: revolucionarios y realistas durante la guerra en Charcas (1809-1813)". Tinkazos, 18 (38), 109-126.

De Gori, E.

(2020)

"Mirar un orden en mutación. Goyeneche, Abascal y Pezuela ante el conflicto altoperuano (inicios del siglo XIX)".e-l@tina. Revista Electrónica de Estudios Latinoamericanos, 18 (70), 40-55. https://publicaciones.sociales.uba.ar/index.php/elatina/article/ view/5151/pdf

Despedida de las chilenas al Egercito Libertador del Perú.

(1820)

s. e. https://archive.org/details/despedidadelasch$00 \mathrm{chil} / \mathrm{page} / \mathrm{n} 1 /$ mode $/ 2 \mathrm{up}$

Díaz-Caballero, J.

(2005) "El incaísmo como primera ficción orientadora en la formación de la nación criolla en las Provincias Unidas del Río de la Plata". A Contracorriente: una Revista de Estudios Latinoamericanos, 3 (1), 67-113.

Earle, R.

(2007) The Return of the Native. Indians and Myth-Making in Spanish America (1810-1830). Duke University Press.

Hobsbawm, E.

(1983) Inventing Tradition and Mass Producing Traditions. Hobsbawm, and Ranger.

Hogan, P. C.

Understanding Nationalism: on Narrative, Cognitive science, and Identity. The Ohio State University Press.

Hunt, L.

(1992) The Family Romance of the French Revolution. University of California Press. 
Jarak, D. A.

(2013) "Bernardo Monteagudo y la 'América, que por desgracia se llamó antes española”. Amerika, (8). https://doi.org/10.4000/amerika.3962

Jelin, E.

(2019) La lucha por el pasado: cómo construimos la memoria social. Siglo XXI Editores.

Jelin, E. y Langland, V.

(2003) Monumentos, memoriales y marcas territoriales, vol. 5. Siglo XXI de Espańa Editores.

Kertzer, D. I.

Ritual, Politics, and Power. Yale University Press.

Lorandi, A. M.

(2015) "Guerra e independencia en los países andinos: la 'traumática transición'”. Andes, 26. https://www.redalyc.org/pdf/127/12743219002.pdf

Madrid, L. A.

(2018) "Artistas y militares afrodescendientes. Un tránsito regional histórico en la coyuntura revolucionaria independentista de Chile". Historia Critica, (70), 6585.

Majluf, N.

(2013) "De cómo reemplazar a un rey: retrato, visualidad y poder en la crisis de la independencia (18081830)". Histórica, 37 (1), 73-108.

Miller, J.

(1918) Memorias del general Miller, al servicio de la República del Perú, vol. 1. Editorial América.

Morán, D.

(2017) La revolución y la guerra de propaganda en América del Sur: itinerarios politicos de la prensa en Lima, Bue- 
nos Aires y Santiago de Chile (1810-1822). (Tesis para optar el grado de doctor en historia). Universidad de Buenos Aires, Facultad de Filosofía y Letras, Buenos Aires.

Munilla, M.

(2000) Celebrar y gobernar: un estudio de las fiestas civicas en Buenos Aires, 1810-1835. Miño y Dávila.

O'Phelan, S.

"The Chilean Irishman Bernardo O'Higgins and the Independence of Peru”. En M. Brown y G. Paquette (Eds.), Connections After Colonialism: Europe and Latin America in the 1820s. University of Alabama Press.

Ortemberg, P.

Rituales del poder en Lima (1732-1828): de la monarquia a la república. Fondo Editorial de la Pontificia Universidad Católica del Perú.

Ortemberg, P. (Ed.).

(2013a) El origen de las fiestas patrias: Hispanoamérica en la era de las independencias. Prohistoria Ediciones.

Ortemberg, P.

(2013b) "Soberanía, guerra y calendarios. Festejos cívicos en Lima desde la crisis monárquica hasta los ańos $s$ posteriores a Ayacucho (1808-1828)". En El origen de las fiestas patrias. Hispanoamérica en la era de las independencias (pp. 109-130). Prohistoria Ediciones.

Ortemberg, P.

(2009) "La entrada de José de San Martín en Lima y la proclamación del 28 de julio: la negociación simbólica de la transición”. Histórica, 33 (2), 65-108. 
Ortemberg, P.

(2006) "Las primeras fiestas cívicas en el Perú independiente: emblemática y ceremonial bajo el Protectorado." Revista Andina, 43, 239-268.

Osorio, C. y Guerrero, C.

(2014) "Exequias dedicadas el día 4 de noviembre de 1817 por el Supremo Gobierno de Chile a la ilustre memoria de los mártires de la libertad en la sangrienta batalla del 1 y 2 de octubre de 1814 en la ciudad de Rancagua”. Cuadernos de Historia (Santiago), (41), 175-188.

Ossa, J. L.

(2016a) “1814 en Chile: de la desobediencia a Lima a la ruptura con España”. Anuario de Estudios Americanos, 73 (1), 231-260.

Ossa, J. L. (2016b)

"El Gobierno de Bernardo O’Higgins visto a través de cinco agentes estadounidenses, 1817-1823". Coherencia, 13 (25): 139-166.

Peralta, P. (2007) ;Chile tiene fiesta!: el origen del 18 de setiembre (18101837). Lom Ediciones.

Pico, R. P. (2012)

"La función política de las celebraciones públicas durante el proceso de independencia de Colombia: en la búsqueda de la legitimidad y la lealtad". Historia y Sociedad, (23), 175-205.

Pinto, J. y Valdivia, V.

(2009) ¿Chilenos todos? La construcción social de la nación (1810-1840). Lom Ediciones. 
Rípodas, D.

"Pensamiento incaico y pensamiento político rioplatense". Jahrbuch für Geschichte Lateinamerikas, (30), 227-258.

Robira, E. (2016)

"La nueva representación simbólica y visual tras la independencia americana”. Dos Puntas, (14), 259268.

Rojas, R. (2017)

La república imaginada: representaciones culturales y discursos politicos en la época de la independencia. Instituto de Estudios Peruanos.

Rosas, C. (2005)

"La reinvención de la memoria. Los incas en los periódicos de Lima y Cusco de la colonia a la república." En L. Millones (Ed.), Ensayos de historia andina (pp. 119-152). Fondo Editorial de la Facultad de Ciencias Sociales de la Universidad Nacional Mayor de San Marcos.

Rosas, C.

(2002) "La imagen de los incas en la Ilustración peruana del siglo XVIII". En J. Flores y R. Varón (Eds.), El hombre y los Andes. Homenaje a Franklin Pease (pp. 10331047). Fondo Editorial de la Pontificia Universidad Católica del Perú.

Sánchez, S.

"Del rey monumentalizado a la patria feminizada. La metamorfosis política en la ciudad de Guatemala a través de las celebraciones festivas (1789-1821)”. En P. Ortemberg (Ed.), El origen de las fiestas patrias. Hispanoamérica en la era de las independencias (pp. 213-236). Prohistoria Ediciones. 
Sánchez, S.

(2001) "Clima, hambre y enfermedad en Lima durante la guerra independentista (1817-1826)". En S. O'Phelan (Comp.), La independencia en el Perú. De los Borbones a Bolivar (pp. 237-263). Instituto Riva Agüero.

Sánchez, S. B.

(2008) "Los festivales de la Revolución francesa: símbolos y sentimientos en las fiestas revolucionarias, 17891799". Procesos: Revista Ecuatoriana de Historia, 27, 43-56.

Sobrevilla, N.

"Las guerras frente a la crisis del orden colonial. Hispanoamérica. 'Hermanos Compañeros y Amigos de sus mismos contrarios': las guerras de independencia en el Sur Andino 1805-1825”. En M. Ternavasio (Comp.), Las guerras frente a la crisis del orden colonial. Hispanoamérica. Programa Buenos Aires de Historia Politica del siglo XX. http://historiapolitica. com/datos/biblioteca/sobrevilla.pdf.

Striker, G.

(2016) Amigos, compatriotas y hermanos": la representación de los indigenas en la prensa de la Revolución (18101816). (Tesis para optar el grado de licenciado en Historia). Universidad Torcuatto Di Tella, Departamento de Historia, Buenos Aires.

252 Valenzuela, J. (2014)

Fiesta, rito y politica. Del Chile borbónico al republicano. Dirección de Bibliotecas, Archivos y Museos.

Vicuña Mackenna, B.

(1882) Vida del capitán jeneral de Chile don Bernardo O'Higgins. Brigadier de la República Arjentina i Gran Mariscal del Perú. Rafael Joven Editor.Bottom of Form 